\title{
CD44 but not CD24 expression is related to poor prognosis in non-cardia adenocarcinoma of the stomach
}

\author{
Xueyuan $\mathrm{CaO}^{1}$, Donghui $\mathrm{CaO}^{2}$, MeiShan $\mathrm{Jin}^{3}$, Zhifang Jia ${ }^{2}$, Fei Kong ${ }^{2}$, Hongxi Ma ${ }^{3}$, Yinping Wang ${ }^{3}$ and Jing Jiang ${ }^{2 *}$
}

\begin{abstract}
Background: Recent studies have focused on the diagnostic and prognostic significance of CD24 and CD44 expression in human cancers. This study aimed to explore changes in CD44 and CD24 expression levels in patients with gastric cancer and to assess their prognostic values.

Methods: CD44 and CD24 expression levels were investigated immunohistochemically in tumor samples from 290 patients with non-cardia gastric adenocarcinoma, of whom 77 had paired adjacent normal gastric mucosa. CD24 and CD44 mRNA levels were determined by quantitative polymerase chain reaction in 34 patients. Serum anti-Helicobacter pylori lgG was detected by enzyme-linked immunosorbent assay. Relationships between CD44 and CD24 protein expression levels and tumor parameters were analyzed and their prognostic values were evaluated by Cox proportional hazards models.

Results: CD24 and CD44 expression levels were significantly higher in patients with gastric cancer compared with those in paired controls (45.5\% vs. $0.0 \%$, and $61.0 \%$ vs. $0.0 \%, P<0.001)$. Among 290 patients, the overall survival rate was significantly higher in CD44(-) compared with CD44(+) patients (log-rank test, $P=0.035)$. However, there was no significant correlation between CD24 expression and overall survival time (log-rank test, $P=0.115$ ). Multivariate regression analysis indicated that positive CD44 expression $(P=0.029)$, TNM staging $(P<0.001)$, and lymphovascular invasion ( $P=0.016)$, but not CD24 expression $(P=0.065)$, were independent prognostic factors in gastric cancer.
\end{abstract}

Conclusions: Individual expression of CD44 was associated with poor survival in patients with gastric carcinoma.

Keywords: CD44, CD24, Prognosis, Gastric cancer, Expression, Helicobacter pylori

\section{Background}

Gastric cancer is the third most common cancer in China. Despite improvements in surgical techniques and the development of new chemotherapeutic regimens, there were 989,600 new cases, and more than 738,000 deaths worldwide in 2008. Half of these cases and deaths were estimated to occur in China. The prognosis for patients with advanced gastric cancer remains poor, even after curative surgery [1-3]. Although many studies have investigated molecular markers for gastric cancer, the mechanisms of carcinogenesis remain obscure. Interactions between genetic susceptibility variants, molecular

\footnotetext{
* Correspondence: jiangjing19702000@jlu.edu.cn

${ }^{2}$ Division of Clinical Epidemiology, First Hospital of Jilin University,

Changchun, Jilin 130021, China

Full list of author information is available at the end of the article
}

alterations, and environmental and lifestyle factors are known to contribute to the development of gastric cancer. TNM staging of gastric carcinoma is used to judge the prognosis, but there is currently no good molecular-based biomarker that can serve as a useful prognostic predictor for advanced gastric cancer [4]. Both CD24 and CD44 are known to contribute to cellular signaling and cell adhesion, and their roles in carcinogenesis have been investigated. CD24 is a mucin-like cell surface protein shown to be associated with malignancy in numerous human-tissue studies [5]. CD44 is a transmembrane glycoprotein involved in cellular adhesion, which has also been shown to be highly expressed in gastric adenocarcinoma [6]. Sheridan et al. demonstrated that the CD44(+)/CD24(-) phenotype of breast cancer cells was associated with invasive properties and poor prognosis [7]. Cancer stem cells 
(CSCs) have recently been identified in human gastric cancer cell lines in several studies [8], and CD44(+)CD24(+) cells have been shown to define a highly tumorigenic, gastric cancer cell population with properties of selfregeneration and multi-lineage differentiation [9]. Weichert et al. showed that cytoplasmic expression of CD24 was independently correlated with shortened survival in colorectal cancer [10]. Yong et al. recently investigated CD44/ CD24 expression in a retrospective analysis of patients with recurrent gastric cancer, but found no associations between individual or combined expression of CD24 and CD44 and the recurrence of gastric cancer [11]. Based on these previous studies, we hypothesized that CD24 and CD44 expression might be correlated with gastric cancer prognosis. The aim of this study was therefore to evaluate the expression levels of CD24 and CD44 in gastric cancer and to evaluate their possible predictive relevance for future clinical practice. Helicobacter pylori infection is considered a risk factor for gastric adenocarcinoma, and a recent study reported that $H$. pylori, via CagA, unveiled CSC-like properties in gastric epithelial cells [12]. We therefore also investigated the correlation between $H$. pylori infection and CD24/CD44 expression.

\section{Methods}

\section{Participants}

A total of 290 patients (221 men and 69 women) with non-cardia gastric adenocarcinoma who underwent radical operation (D1+ or D2) at the First Hospital of Jilin University were enrolled in this study between August 2000 and December 2010. The patients did not receive any preoperative chemo-radiotherapy. Postoperative chemotherapy was administered to all patients with stages II, III, and IV tumors. The diagnosis of gastric cancer was made on the bases of morphologic and immunohistochemical findings, evaluated independently by two pathologists (MJ and YW). Tumor samples were collected at surgery. Histopathological classification and grades of adenocarcinoma were defined according to the Laurén classification [13] and World Health Organization (WHO) classification 2010 [14]. They included papillary adenocarcinoma $(n=$ $4)$, tubular adenocarcinoma $(\mathrm{n}=252)$, mucinous adenocarcinoma $(n=27)$, and poorly cohesive carcinomas (signet ring cell carcinoma) $(\mathrm{n}=7)$ according to WHO classification 2010. Adjacent normal gastric epithelial samples were also collected from 77 patients for comparison. Patient ages were from 32 to 87 years, with a median age of 64 years. Written informed consent was obtained from all the patients and the study protocol was approved by the Ethics Committee of the First Hospital of Jilin University.

\section{Immunohistochemistry}

Tissue blocks were constructed using a tissue array (Minicore; Alphelys Impasse Paul Langevin, Plaisir, France).
Sections ( $4 \mu \mathrm{m}$ thick) were cut, deparaffinized, and stained using a streptavidin-biotin immunoperoxidase technique. The sections were then incubated with an anti-human CD24 polyclonal antibody (1:100 diluted, sc-7034; Santa Cruz, USA) and a CD44 monoclonal antibody (1:50 diluted, MA1-81995; Thermo Fisher Scientific Inc., Chicago, IL, USA), respectively. 3, 3-Diaminobenzidine was employed as a chromogen. Sections were counterstained with hematoxylin. Slides treated with IgG isotypes instead of primary antibodies were used as negative controls. The stained slides were evaluated independently by two pathologists (MJ and YW) who were blinded to the clinical data and outcomes. Staining intensity and percentages of cells stained at a specific magnitude of intensity were assessed using the widely accepted HSCORE system. The HSCORE was calculated using the following equation: $\operatorname{HSCORE}=\sum \operatorname{Pi}(\mathrm{i})(\mathrm{I}=0,1,2,3, \mathrm{Pi}=0-100 \%)$, where i represents the staining intensity, i.e., $0=$ no staining, $1=$ weak staining, $2=$ moderate staining, and $3=$ strong staining. (Additional file 1: Figure S1) Photographs of the reference intensities are shown in the supplemental data. Given that Pi represents the percentage of stained cells with intensities varying from 0 to $100 \%$, the final HSCORE varied from 0 to 300 . The percentages of positive cells were counted in at least 50 fields by examining at least 1000 cells under a microscope, using a $40 \times$ objective lens. The expression levels of $\mathrm{CD} 24$ and $\mathrm{CD} 44$ were classified as negative (HSCORE $<30)$ and positive (HSCORE $\geq 30$ ). Cut-off values for CD24 and CD44 (HSCORE < 30) were modified according to the results of previous studies $[11,15]$.

\section{Reverse transcription-polymerase chain reaction quantification of CD24 and CD44}

Expression levels of CD24 and CD44 mRNA were determined in 34 patients with gastric cancer. Briefly, RNA was extracted from stomach tissues using an RNA Isolation Kit (Axygen, CA, USA) according to the manufacturer's guidelines. After DNase treatment, first-strand cDNA was synthesized using a cDNA synthesis kit (Roche, Basel, Switzerland). Quantitative polymerase chain reaction of CD24 (forward primer: AAA CAA CAA CTG GAA CTT CAA GTA ACT C, reverse primer: GGT GGT GGC ATT AGT TGG ATT T) and CD44v6 (forward primer: TCC CTG CTA CCA ATA GGA ATG ATG, reverse primer: GGT CAC TGG GAT GAA GGT CC) was performed using the Light Cycler 480 system (Roche). Glyceraldehyde 3-phosphate dehydrogenase (GAPDH) was quantified as an endogenous RNA control (forward primer: TGC ACC ACC AAC TGC TTA GC, reverse primer: GGC ATG GAC TGT GGT CAT GAG).

\section{Determination of $H$. pylori infection}

Blood samples were collected from 103 patients to determine the presence of $H$. pylori infection before surgery. 


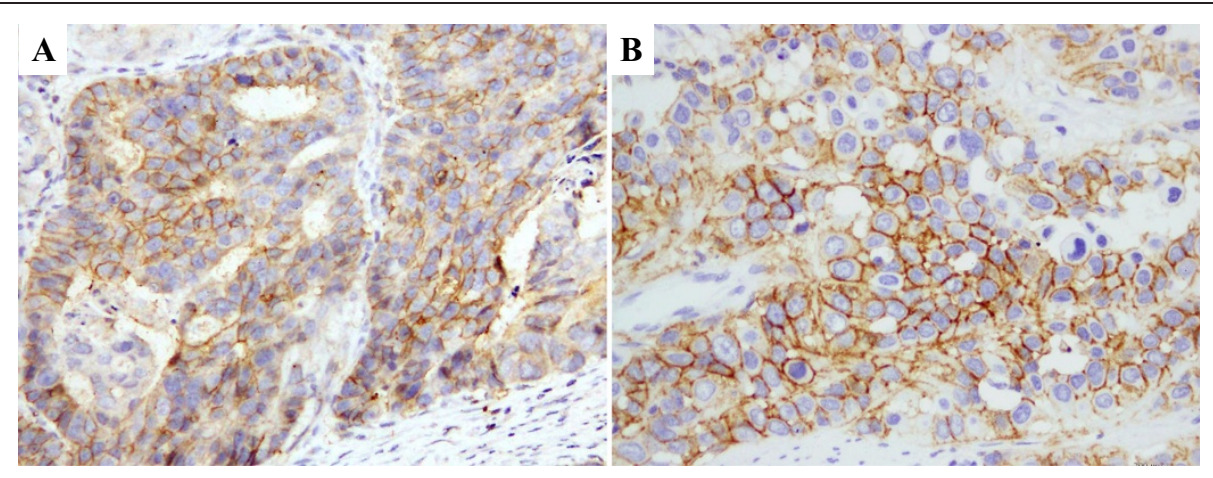

Figure 1 Visualization of CD24 and CD44 expression in gastric cancer cells by immunohistochemistry. CD24 (A) and CD44 (B) immunostaining in the membrane of gastric carcinoma cells.

Serum anti-H. pylori IgG was detected by enzyme-linked immunosorbent assay (Biohit, Helsinki, Finland). Briefly, samples with titers above the cut-off value of 30 EIU were considered as positive for $H$. pylori infection, as described previously [16].

\section{Statistical analysis}

The HSCOREs for CD24 and CD44 expression were presented as medians (interquartile range). MannWhitney U, Kruskal-Wallis H, and Wilcoxon signed rank tests were used to compare results between groups. The Kaplan-Meier method was used to estimate the overall survival rate, and survival differences were analyzed using log-rank tests. A Cox proportional hazards model was used to calculate the relative risks and corresponding 95\% confidence intervals (CI), after adjusting for age, sex, lymphovascular invasion, and TNM staging. Analyses were performed using SPSS software 18.0 (SPSS Inc., USA). All statistical tests were two-tailed and $P$ values $<0.05$ were considered to be statistically significant.

\section{Results}

\section{CD24 and CD44 expression levels in gastric cancer}

CD24 and CD44 expression were detected in the membrane of cancer cells in gastric cancer samples (Figure 1). Weak staining for both CD24 and CD44 was also observed in the nucleus of gastric cancer cells. All negative controls demonstrated negligible background staining. Among 77 paired samples, CD24(+) and CD44(+) staining results were found in $35 / 77$ (45.5\%) and 47/77 (61.0\%) of the gastric cancer samples, respectively. However, the paired normal gastric epithelial cells showed negative expression of CD24 and CD44. mRNA expression levels of both CD24 and CD44 were significantly higher in immunohistochemically positive compared with immunohistochemically negative groups. The mRNA expression levels of CD24 and CD44 were consistent with the immunohistochemistry results in gastric cancer (Figure 2).

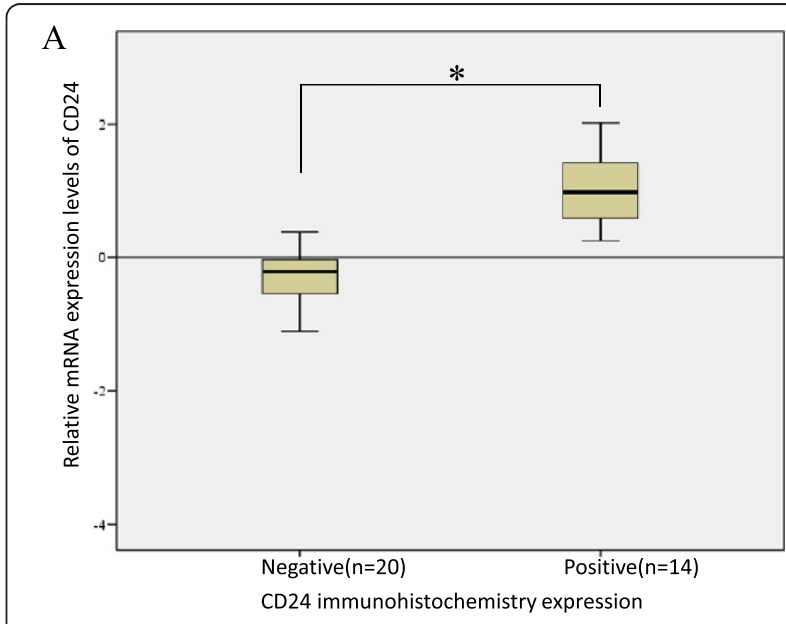

B

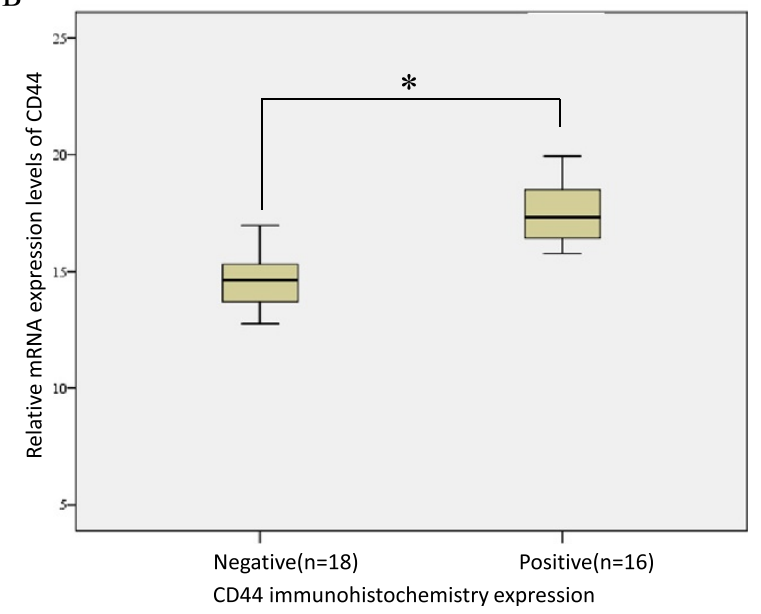

Figure 2 mRNA expression levels of CD24 and CD44.

Quantification by reverse transcription-polymerase chain reaction showed that CD24 (A) and CD44 (B) levels were significantly higher in immunohistochemically positive compared with immunohistochemically negative groups, respectively. ${ }^{*}, P<0.001$. 


\section{Correlations between CD24/CD44 expression levels and clinicopathologic parameters}

Patients with lymphovascular invasion had significantly higher rates of CD44 positivity than those without invasion $(P=0.013)$. CD24 and CD44 expression levels were also analyzed according to age, sex, tumor differentiation, depth of invasion, lymph node metastasis, and TNM stage. However, there were no significant differences in CD24/CD44 expression levels in relation to these parameters. The clinical characteristics of the subjects are summarized in Table 1.

Table 1 CD24 and CD44 expressions in gastric carcinomas according to clinicopathological parameters

\begin{tabular}{|c|c|c|c|c|}
\hline & CD24 positive rate $\mathrm{n}(\%)$ & $P$ value & CD44 positive rate $\mathrm{n}(\%)$ & $P$ value \\
\hline \multicolumn{5}{|l|}{ Gender } \\
\hline Male $(n=221)$ & $92(41.6)$ & 0.148 & 133(60.2) & 0.835 \\
\hline Female $(n=69)$ & 22(31.9) & & $45(65.2)$ & \\
\hline \multicolumn{5}{|l|}{ Age(y) } \\
\hline$\leq 60(n=127)$ & $48(37.8)$ & 0.435 & $85(66.9)$ & 0.087 \\
\hline$>60(n=163)$ & $69(42.3)$ & & 93(57.0) & \\
\hline \multicolumn{5}{|l|}{ H.pylori infection $(n=103)$} \\
\hline Positive $(n=67)$ & 24(35.8) & 0.096 & 48(71.6) & 0.815 \\
\hline Negative $(n=36)$ & 19(52.8) & & $25(69.4)$ & \\
\hline \multicolumn{5}{|l|}{ Lauren classification } \\
\hline Intestinal type $(n=104)$ & $42(40.3)$ & 0.965 & $67(64.4)$ & 0.168 \\
\hline Diffuse type $(n=186)$ & $77(41.3)$ & & 103(55.3) & \\
\hline \multicolumn{5}{|l|}{ WHO classification } \\
\hline Papillary adenocarcinoma $(n=4)$ & $1(25.0)$ & 0.906 & $4(100.0)$ & 0.064 \\
\hline \multicolumn{5}{|l|}{ Tubular adenocarcinoma } \\
\hline Well $(n=1)$ & $0(0.0)$ & & $0(0.0)$ & \\
\hline Moderate $(n=98)$ & 30(30.6) & & $49(50.0)$ & \\
\hline Poor $(n=153)$ & $47(30.7)$ & & $87(56.9)$ & \\
\hline Mucinous adenocarcinoma $(n=27)$ & $7(25.9)$ & & $13(48.1)$ & \\
\hline Poorly cohesive carcinomas (Signet ring cell carcinomas) $(n=7)$ & $1(14.3)$ & & $1(14.3)$ & \\
\hline \multicolumn{5}{|l|}{ Lymph-vascular invasion } \\
\hline Absent $(n=134)$ & $56(41.8)$ & 0.642 & $72(53.7)$ & 0.013 \\
\hline Present $(n=156)$ & $61(39.1)$ & & $106(67.9)$ & \\
\hline \multicolumn{5}{|l|}{ TNM stage } \\
\hline$I(n=23)$ & $10(43.5)$ & 0.844 & 16(69.6) & 0.559 \\
\hline$\|(n=47)$ & 19(40.4) & & $32(68.1)$ & \\
\hline III $(n=187)$ & $77(41.2)$ & & 110(58.9) & \\
\hline IV $(n=33)$ & $11(33.3)$ & & 20(60.6) & \\
\hline \multicolumn{5}{|l|}{ Invasion } \\
\hline $\mathrm{T1}(\mathrm{n}=9)$ & $2(22.2)$ & 0.537 & $7(77.8)$ & 0.485 \\
\hline$T 2(n=36)$ & 14(38.9) & & $22(61.1)$ & \\
\hline $\mathrm{T} 3(\mathrm{n}=212)$ & $85(40.1)$ & & $132(62.2)$ & \\
\hline T4 $(n=33)$ & $16(48.5)$ & & $17(51.5)$ & \\
\hline \multicolumn{5}{|l|}{ Lymph node metastasis } \\
\hline No $(n=62)$ & $27(43.5)$ & 0.445 & $40(64.5)$ & 0.534 \\
\hline N1 $(n=89)$ & $39(43.8)$ & & $49(55.1)$ & \\
\hline$N 2(n=74)$ & $24(32.4)$ & & $47(63.5)$ & \\
\hline N3 $(n=65)$ & $27(41.5)$ & & $42(64.6)$ & \\
\hline \multicolumn{5}{|l|}{ Survival } \\
\hline Survived $(n=171)$ & $62(36.3)$ & 0.089 & $96(56.1)$ & 0.028 \\
\hline Died $(n=119)$ & $55(46.2)$ & & $82(68.9)$ & \\
\hline
\end{tabular}




\section{CD44 expression was associated with poor survival}

Follow-up information was available for all 290 patients for periods of 3-135 months (median 41 months). No patient died of postoperative complications within 30 days of the beginning of the study period, but 119 (41.0\%) patients died during the follow-up period. The overall survival time was significantly longer in CD44(-) compared with CD44(+) patients (Figure 3A; log-rank test, $P=0.035)$. Although patients with CD24(-) tumors showed a trend towards longer overall survival trend, the difference was not significant (Figure 3B; log-rank test, $P=0.115$ ). TNM stage and lymphovascular invasion were significantly related to postoperative survival time (Figure 3C,D).

\section{CD44 expression was an independent prognostic marker} After adjusting for sex, age, TNM stage, and lymphovascular invasion, CD44(+) patients had a significantly higher risk of gastric cancer-related death compared with CD44(-) patients (odds ratio $(\mathrm{OR})=1.57 ; 95 \% \mathrm{CI}$ : 1.05-2.36; $P=$ 0.029). Compared with patients who were CD24(-), CD24(+) patients had a higher likelihood of shorter overall survival, though the difference was not significant $(\mathrm{OR}=1.41 ; 95 \% \mathrm{CI}: 0.98-2.02 ; P=0.065)$. Multivariate analyses identified CD44 expression, TNM stage, and lymphovascular invasion as independent prognostic factors of poor patient survival in gastric cancer (Table 2).

\section{CD24/CD44 expression levels and $H$. pylori infection}

Helicobacter pylori infection was detected in 67 of the 103 (65.4\%) gastric cancer patients tested. However, there was no correlation between $H$. pylori infection and CD44 expression $(P=0.815)$, and no significant association between $H$. pylori infection and CD24 expression $(P=0.096)$.
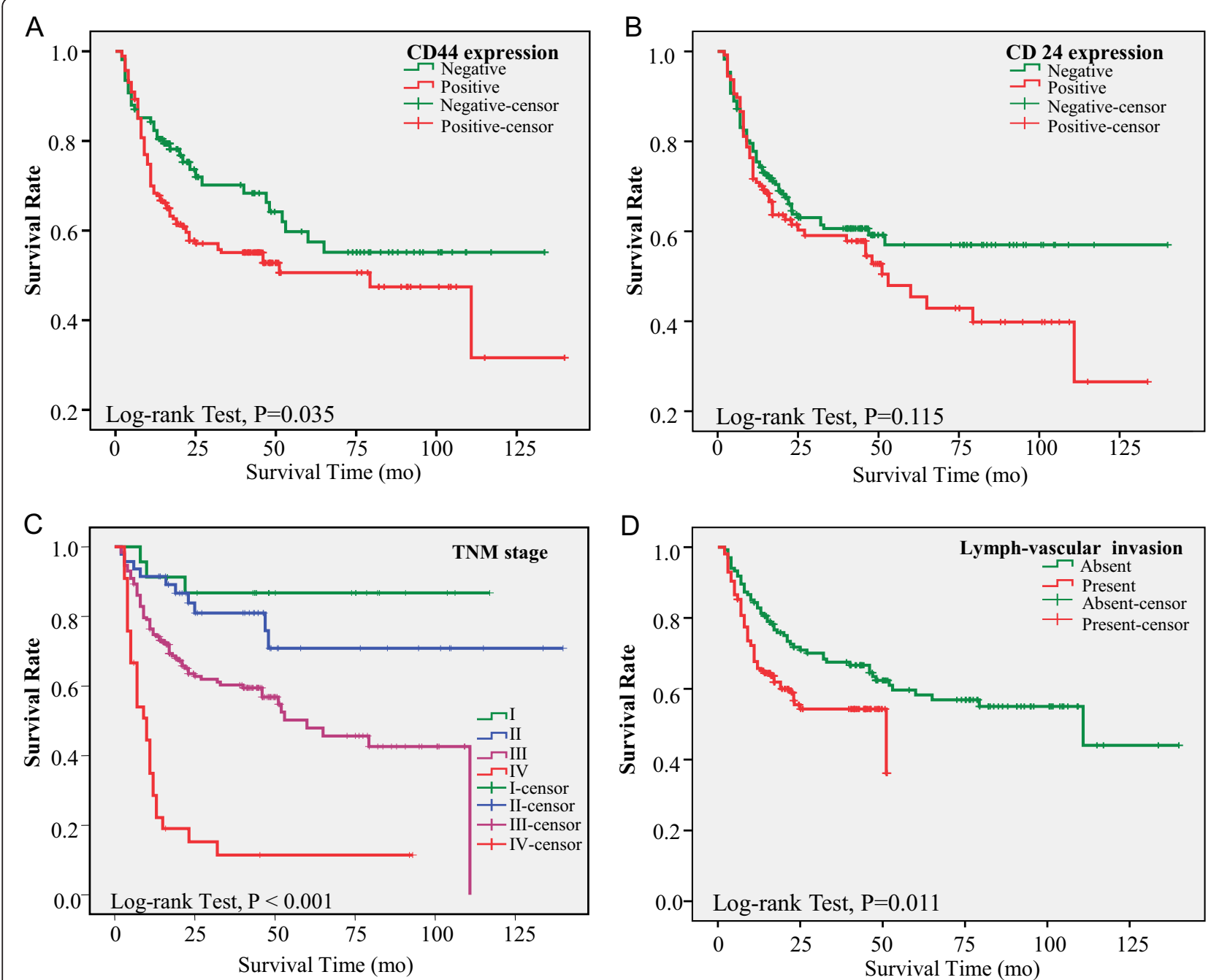

Figure 3 Factors affecting overall survival in patients with gastric cancer. Note no significant correlation between CD24 expression and overall survival time (B). However CD44 expression (A), TNM staging (C), and lymphovascular invasion (D) were significantly associated with poor survival in gastric cancer. 
Table 2 Multivariate analysis with Cox proportional hazards model for prediction of overall survival in patients with gastric cancer

\begin{tabular}{llc}
\hline & Relative risk (95\% Cl) & P value \\
\hline CD44 expression & & \\
\hline Negative $(n=112)$ & Reference & 0.029 \\
\hline Positive $(n=178)$ & $1.57(1.05-2.36)$ & \\
\hline CD24 expression & & \\
\hline Negative $(n=173)$ & Reference & 0.065 \\
\hline Positive $(n=117)$ & $1.41(0.98-2.02)$ & \\
\hline TNM staging & & 0.433 \\
\hline I ( $n=23)$ & Reference & 0.015 \\
\hline II ( $n=47)$ & $1.69(0.46-6.24)$ & $<0.001$ \\
\hline III ( $n=187)$ & $4.32(1.33-14.01)$ \\
\hline IV ( $n=33)$ & $14.53(4.27-49.41)$ & 0.016 \\
\hline Lymph-vascular invasion & & \\
\hline Absent $(n=134)$ & Reference & \\
\hline Present $(n=156)$ & $1.60(1.09-2.35)$ & \\
\hline *Cox proportional hazards model, adjusted for gender, age,venous infiltration, \\
TNM staging.
\end{tabular}

\section{Discussion}

Several recent studies have focused on the diagnostic and prognostic significance of CD24 and CD44 expression in human cancers [17-19], and the roles of CD24 and CD44 in gastric carcinoma have also been explored $[6,11,20,21]$. Takahashi et al. reported that CD24 upregulation was significantly associated with depth of invasion and high pathological stage in 173 patients with gastric cancer [22]. The frequency of CD44 expression in gastric cancer varies widely from 31 to $72 \%$. Ozmen et al. reported significant correlations between CD44 over-expression and perineural invasion and lymph node positivity in gastric cancers [23]. The present study simultaneously analyzed CD24 and CD44 expression levels independently and showed that positive expression of CD44 alone, but not CD24, was associated with poor survival in gastric carcinoma. No CD24(+) or CD44(+) staining was found in normal gastric surface epithelium in the present study, though Bessède et al. did detect CD44 expression in normal gastric mucosa [12]. Further studies are needed to explain this apparent discrepancy. CD24 is a mucin-type glycosylphosphatidylinositollinked cell surface protein that is expressed in developing or regenerating tissue, and in ovarian cancer and hepatocellular carcinoma [20,24]. Previous investigation of the correlation between CD24/CD44 expression and gastric cancer revealed that CD24(+) patients had a higher likelihood of gastric cancer recurrence than CD24(-) patients [11]. However, the biological function of CD24 in carcinogenesis remains unknown. Previous studies observed relationships between high CD24 expression and lymph node metastasis, venous invasion, and lymphatic invasion. However, although the present study found a trend towards shorter survival in CD24(-) compared with CD24(+) patients, the difference was not significant. Duckworth et al. detected CD24 expression in gastric parietal cells and showed that it regulated apoptosis and the response to Helicobacter felis infection in a mouse model [25]. However, the current study found no significant association between Helicobacter infection and CD24 expression. One possible explanation for the significant association between CD44 and survival may be related to the stem cell function of CD44(+) cells [26-29]. In 2009, Takaishi et al. first demonstrated the existence of CD44(+) cells endowed with stem cell properties in gastric tumors. They reported that $\mathrm{CD} 44(+)$ gastric cancer cells showed the stem cell characteristics of self-renewal and the ability to form differentiated progeny and give rise to $\mathrm{CD} 44(-)$ cells. Takaishi et al. further verified CD44 as a cell surface marker of gastric CSCs in several human gastric cancer cell lines, and demonstrated that CD44(+) gastric cancer cells showed increased resistance to chemotherapy- or radiation-induced cell death [29]. Liu et al. reported that CD44 was a direct and relevant downstream target of miR-34a in prostate cancer. CD44 protein levels were decreased in cells over-expressing miR-34a, and knock down of CD44 functionally mimicked the miR-34a effects of inhibition of tumor development and metastasis [30]. We therefore considered that higher expression of CD44 in gastric cancer cells may represent a higher percentage of CSCs, thus explaining why CD44(+) patients demonstrate poorer overall survival than CD44(-) patients. Further studies are warranted to investigate the mechanisms of miRNA regulation of CSCs.

\section{Conclusions}

In conclusion, expression of CD44 was associated with poor survival in patients with gastric carcinoma. This suggests that CD44 may be a clinically useful prognostic marker, and may also represent a useful therapeutic target. However, the functions of CD24 and CD44 in gastric carcinogenesis remain unclear [31,33], and further studies are needed to clarify their roles.

\section{Additional file}

Additional file 1: Figure S1. Photographies of the CD44

immunohistochemistry staining intensities: $0,1,2$ and 3 .

\section{Competing interests}

The authors declare that they have no competing interests.

Authors' contributions

$J J$ and $X C$ designed the study and carried out most of the study; JJ and XC wrote the first draft of the manuscript; DC performed the molecular experiments; HM performed the pathology experiments; MJ, YW, and FK analyzed the pathological data; DC, ZJ, and FK collected patients' clinical 
information; JJ performed the statistical analysis. All authors read and approved the final manuscript.

\section{Acknowledgments}

This work was supported by the Norman Bethune Program of Jilin University [2013025], and the National Natural Science Foundation of China (81072369 and 81273065).

\section{Author details}

${ }^{1}$ Department of Gastric and Colorectal Surgery, First Hospital of Jilin University, Changchun, Jilin 130021, China. 'Division of Clinical Epidemiology, First Hospital of Jilin University, Changchun, Jilin 130021, China. ${ }^{3}$ Division of Pathology, First Hospital of Jilin University, Changchun, Jilin 130021, China.

Received: 31 January 2014 Accepted: 9 September 2014

Published: 12 September 2014

\section{References}

1. Mathers CD, Loncar D: Projections of global mortality and burden of disease from 2002 to 2030. PLoS Med 2006, 3(11):e442.

2. Jemal A, Bray F, Center MM, Ferlay J, Ward E, Forman D: Global cancer statistics. CA Cancer J Clin 2011, 61(2):69-90.

3. Shiraishi N, Sato K, Yasuda K, Inomata M, Kitano S: Multivariate prognostic study on large gastric cancer. J Surg Oncol 2007, 96(1):14-18.

4. Sasako M, Inoue M, Lin JT, Khor C, Yang HK, Ohtsu A: Gastric cancer working group report. Jpn J Clin Oncol 2010, 40(Suppl 1):i28-i37.

5. Thomas S, Harding MA, Smith SC, Overdevest JB, Nitz MD, Frierson HF, Tomlins SA, Kristiansen G, Theodorescu D: CD24 is an effector of HIF-1-driven primary tumor growth and metastasis. Cancer Res 2012, 72(21):5600-5612.

6. Ghaffarzadehgan K, Jafarzadeh M, Raziee HR, Sima HR, Esmaili-Shandiz E, Hosseinnezhad H, Taghizadeh-Kermani A, Moaven O, Bahrani M: Expression of cell adhesion molecule CD44 in gastric adenocarcinoma and its prognostic importance. World J Gastroenterol 2008, 14(41):6376-6381.

7. Sheridan C, Kishimoto H, Fuchs RK, Mehrotra S, Bhat-Nakshatri P, Turner CH, Goulet R Jr, Badve S, Nakshatri H: CD44+/CD24- breast cancer cells exhibit enhanced invasive properties: an early step necessary for metastasis. Breast Cancer Res 2006, 8(5):R59.

8. Haraguchi N, Utsunomiya T, Inoue H, Tanaka F, Mimori K, Barnard GF, Mori $\mathrm{M}$ : Characterization of a side population of cancer cells from human gastrointestinal system. Stem Cells 2006, 24(3):506-513.

9. Zhang C, Li C, He F, Cai Y, Yang H: Identification of CD44 + CD24+ gastric cancer stem cells. J Cancer Res Clin Oncol 2011, 137(11):1679-1686.

10. Weichert W, Denkert C, Burkhardt M, Gansukh T, Bellach J, Altevogt P, Dietel $M$, Kristiansen G: Cytoplasmic CD24 expression in colorectal cancer independently correlates with shortened patient survival. Clin Cancer Res 2005, 11(18):6574-6581.

11. Yong CS, Ou Yang CM, Chou YH, Liao CS, Lee CW, Lee CC: CD44/CD24 expression in recurrent gastric cancer: a retrospective analysis. $B M C$ Gastroenterol 2012, 12:95.

12. Bessede E, Staedel C, Acuna Amador LA, Nguyen PH, Chambonnier L, Hatakeyama M, Belleannee G, Megraud F, Varon C: Helicobacter pylori generates cells with cancer stem cell properties via epithelialmesenchymal transition-like changes. Oncogene 2014, 33(32):4123-4131.

13. Lauren P: The Two histological main types of gastric carcinoma: diffuse and So-called intestinal-type carcinoma. An attempt at a histo-clinical classification. Acta Pathol Microbiol Scand 1965, 64:31-49.

14. Bosman FT, Carneiro F, Hruban RH, Theise ND: WHO classification of tumors of the digestive system. 4th edition. Lyon: IARC Press; 2010.

15. Chen S, Hou JH, Feng XY, Zhang XS, Zhou ZW, Yun JP, Chen YB, Cai MY Clinicopathologic significance of putative stem cell marker, CD44 and CD133, in human gastric carcinoma. J Surg Oncol 2013, 107(8):799-806

16. Cao XY, Jia ZF, Jin MS, Cao DH, Kong F, Suo J, Jiang J: Serum pepsinogen II is a better diagnostic marker in gastric cancer. World J Gastroenterol 2012, 18(48):7357-7361

17. Darwish NS, Kim MA, Chang MS, Lee HS, Lee BL, Kim Yl, Kim WH: Prognostic significance of CD24 expression in gastric carcinoma. Cancer Res Treat 2004, 36(5):298-302.

18. Overdevest JB, Thomas S, Kristiansen G, Hansel DE, Smith SC, Theodorescu D: CD24 offers a therapeutic target for control of bladder cancer metastasis based on a requirement for lung colonization. Cancer Res 2011, 71(11):3802-3811.

19. Wakamatsu Y, Sakamoto N, Oo HZ, Naito Y, Uraoka N, Anami K, Sentani K, Oue N, Yasui W: Expression of cancer stem cell markers ALDH1, CD44 and CD133 in primary tumor and lymph node metastasis of gastric cancer. Pathol Int 2012, 62(2):112-119.

20. Yang XR, Xu Y, Yu B, Zhou J, Li JC, Qiu SJ, Shi YH, Wang XY, Dai Z, Shi GM, Wu B, Wu LM, Yang GH, Zhang BH, Qin WX, Fan J: CD24 is a novel predictor for poor prognosis of hepatocellular carcinoma after surgery. Clin Cancer Res 2009, 15(17):5518-5527.

21. Kim K, Min HS, Chie EK, Jang JY, Kim SW, Han SW, Oh DY, Im SA, Kim TY, Bang YJ, Jang JJ, Ha SW: CD24 expression predicts distant metastasis in extrahepatic bile duct cancer. World J Gastroenterol 2013, 19(9):1438-1443.

22. Takahashi M, Nakajima M, Ogata H, Domeki Y, Ohtsuka K, Ihara K, Kurayama E, Yamaguchi S, Sasaki K, Miyachi K, Kato H: CD24 expression is associated with progression of gastric cancer. Hepatogastroenterology 2013, 60(124):653-658.

23. Ozmen F, Ozmen MM, Ozdemir E, Moran M, Seckin S, Guc D, Karaagaoglu E, Kansu E: Relationship between LYVE-1, VEGFR-3 and CD44 gene expressions and lymphatic metastasis in gastric cancer. World J Gastroenterol 2011, 17(27):3220-3228.

24. Kristiansen G, Denkert C, Schluns K, Dahl E, Pilarsky C, Hauptmann S: CD24 is expressed in ovarian cancer and is a new independent prognostic marker of patient survival. Am J Pathol 2002, 161(4):1215-1221.

25. Duckworth CA, Clyde D, Pritchard DM: CD24 is expressed in gastric parietal cells and regulates apoptosis and the response to Helicobacter felis infection in the murine stomach. Am J Physiol Gastrointest Liver Physiol 2012, 303(8):G915-G926.

26. Chen W, Zhang X, Chu C, Cheung WL, Ng L, Lam S, Chow A, Lau T, Chen M, Li Y, Nie Y, Wong BC, Pang R: Identification of CD44+ cancer stem cells in human gastric cancer. Hepatogastroenterology 2013, 60(124):949-954.

27. Saito S, Okabe H, Watanabe M, Ishimoto T, Iwatsuki M, Baba Y, Tanaka Y, Kurashige J, Miyamoto $Y$, Baba H: CD44v6 expression is related to mesenchymal phenotype and poor prognosis in patients with colorectal cancer. Oncol Rep 2013, 29(4):1570-1578.

28. Mima K, Okabe H, Ishimoto T, Hayashi H, Nakagawa S, Kuroki H, Watanabe M, Beppu T, Tamada M, Nagano O, Saya H, Baba H: CD44s regulates the TGF-beta-mediated mesenchymal phenotype and is associated with poor prognosis in patients with hepatocellular carcinoma. Cancer Res 2012, 72(13):3414-3423.

29. Takaishi S, Okumura T, Tu S, Wang SS, Shibata W, Vigneshwaran R, Gordon SA, Shimada Y, Wang TC: Identification of gastric cancer stem cells using the cell surface marker CD44. Stem Cells 2009, 27(5):1006-1020.

30. Liu C, Kelnar K, Liu B, Chen X, Calhoun-Davis T, Li H, Patrawala L, Yan H, Jeter C, Honorio S, Wiggins JF, Bader AG, Fagin R, Brown D, Tang DG: The microRNA miR-34a inhibits prostate cancer stem cells and metastasis by directly repressing CD44. Nat Med 2011, 17(2):211-215.

31. Chou YY, Jeng YM, Lee TT, Hu FC, Kao HL, Lin WC, Lai PL, Hu RH, Yuan RH: Cytoplasmic CD24 expression is a novel prognostic factor in diffuse-type gastric adenocarcinoma. Ann Surg Oncol 2007, 14(10):2748-2758.

32. Ryu HS, do Park J, Kim HH, Kim WH, Lee HS: Combination of epithelialmesenchymal transition and cancer stem cell-like phenotypes has independent prognostic value in gastric cancer. Hum Pathol 2012, 43(4):520-528.

33. Buck K, Hug $S$, Seibold P, Ferschke I, Altevogt $P$, Sohn C, Schneeweiss A, Burwinkel B, Jager D, Flesch-Janys D, Chang-Claude J, Marme F: CD24 polymorphisms in breast cancer: impact on prognosis and risk. Breast Cancer Res Treat 2013, 137(3):927-937.

doi:10.1186/1471-230X-14-157

Cite this article as: Cao et al:: CD44 but not CD24 expression is related to poor prognosis in non-cardia adenocarcinoma of the stomach. BMC Gastroenterology 2014 14:157. 